\title{
A MODEL OF THE OPEN MARKET OPERATIONS OF THE EUROPEAN CENTRAL BANK
}

Juan Ayuso and Rafael Repullo 


\title{
A MODEL OF THE OPEN MARKET OPERATIONS OF THE EUROPEAN CENTRAL BANK(*)
}

\author{
Juan Ayuso \\ BANCO DE ESPAÑA \\ Rafael Repullo \\ CEMFI AND CPR
}

(*) The views expressed in this paper are those of its authors and do not necessarily reflect the position of the Banco de España. We thank Manuel Arellano, Margarita Catalão Lopes, Julio Segura, and Chris Waller for helpful comments. We also thank seminar participants at the Banco de España, the Purdue Conference on Money and Payment Systems, and Frankfurt Conference on Central Bank Operations. E-mail addresses: ayuso@bde.es; repullo@cemfi.es.

Banco de España - Servicio de Estudios

Documento de Trabajo no 0016 
In publishing this series the Banco de España seeks to disseminate studies of interest that will help acquaint readers better with the Spanish economy.

The analyses, opinions and findings of these papers represent the views of their authors; they are not necessarily those of the Banco de España.

The Banco de España disseminates its main reports and most of its publications via the INTERNET at the following website:

http://www.bde.es

ISSN: 0213-2710

ISBN: 84-7793-723-0

Depósito legal: M. 40536-2000

Imprenta del Banco de España 


\begin{abstract}
We construct a model to analyze the two types of tender procedures used by the European Central Bank (ECB) in its open market operations. We assume that the ECB minimizes the expected value of a loss function that depends on the quadratic difference between the interbank rate and a target interest rate that characterizes the stance of monetary policy. We show that when the loss function penalizes more heavily interbank rates below the target, fixed rate tenders have a unique equilibrium characterized by extreme overbidding. We also show that variable rate tenders have multiple equilibria characterized by varying degrees of overbidding, and that in these tenders an equilibrium without overbidding can be obtained by preannouncing the intended liquidity injection. Finally, our empirical analysis supports the assumption of an asymmetric loss function for the ECB.
\end{abstract}





\section{Introduction}

The monetary policy instruments chosen by the European Central Bank (ECB) ${ }^{1}$ in order to implement its monetary policy are (i) minimum required reserves, (ii) open market operations, and (iii) standing facilities. The reserve requirement helps to ensure that the euro area banking system has an aggregate liquidity deficit which is covered by two main types of open market operations: the main refinancing operations and the longer-term refinancing operations. The former (latter) are liquidity providing collateralized transactions with a weekly (monthly) frequency and a maturity of two weeks (three months). The banks can also obtain or place overnight liquidity at the marginal lending and deposit standing facilities.

The refinancing operations can be conducted via either fixed rate or variable rate tenders. In fixed rate tenders the ECB announces an interest rate and the banks bid the amount of liquidity they want to borrow at this rate. If the aggregate amount bid exceeds the amount of liquidity that the ECB wants to provide, each bank receives a pro rata share of this liquidity. In variable rate tenders the banks bid the amounts they want to borrow and the interest rates they are willing to pay. In this case, bids with successively lower interest rates are accepted until the total liquidity to be allotted is exhausted.

Up to now the longer-term refinancing operations have been conducted via variable rate tenders. On the other hand, from the beginning of the Monetary Union in January 1999 until June 2000 the main refinancing operations were conducted via fixed rate tenders. A striking feature of these tenders was the very high degree of overbidding by the banks. For example, the median allotment ratio (i.e. the ratio between the allotted amount and the total amount bid) during this period was $6.10 \%$, with a minimum value of only $0.87 \%$. In fact, the decision to switch to variable rate tenders taken by the Governing Council of the ECB in June 2000 was justified as "...a response to the severe overbidding which has developed in the context of the current fixed rate tender procedure." 2

\footnotetext{
${ }^{1}$ Strictly speaking we should refer to the monetary policy of the Eurosystem, which comprises the ECB and the national central banks of the countries that have adopted the euro. However since the Eurosystem has no legal personality and is governed by the decision-making bodies of the ECB, with a slight abuse of terminology, in this paper we will simply use the latter term.

${ }^{2}$ The switch to variable rate tenders had been advocated among others by the 1999 International
} 
The purpose of this paper is to propose a theoretical model of the tender procedures used by the ECB in order to analyze the equilibrium behavior of the banks under fixed and variable rate tenders. The model can shed light on various issues like the source of the overbidding in fixed rate tenders, the differences between single variable rate tenders (also known as uniform or "Dutch") and multiple variable rate tenders (also known as discriminatory or "American"), and the possible effects (in both fixed and variable rate tenders) of announcing the desired liquidity injection prior to the tender.

The model has a large number of identical risk neutral banks that can obtain liquidity from the central bank or in an interbank market. The central bank provides liquidity through a fixed or a variable rate tender. It is assumed that the interbank interest rate is a decreasing function of the liquidity allotted by the central bank in the tender, and also depends on the realization of a liquidity shock. The main difference between this setup and a standard multiple unit auction is that the seller (the central bank) does not want to maximize revenue. Instead, the central bank wants to steer the interbank rate towards a target rate that characterizes the stance of monetary policy. ${ }^{3}$ Formally, we assume that the central bank minimizes the expected value of a loss function that depends on the quadratic difference between the interbank rate and the target rate. This expectation is taken conditional on the information collected by the central bank on the future realization of the liquidity shock.

We show that when the loss function of the central bank is symmetric, fixed and variable rate tenders (both Dutch and American) have the same multiple equilibrium outcomes. Moreover, in these outcomes there is always some overbidding. On the other hand, when the loss function of the central bank is asymmetric in the sense of penalizing more heavily interbank rates below the target, then the nature of equilibria does not change for variable rate tenders, but fixed rate tenders have now a unique equilibrium characterized by extreme overbidding. In addition, we show that except in this latter case, the set of equilibrium outcomes becomes larger (and even includes an equilibrium without overbidding) when the central bank announces its intended

Capital Markets report of the International Monetary Fund, and the 2000 Monitoring the European Central report of the Centre for Economic Policy Research.

${ }^{3}$ In the 1999 Annual Report it is stated that "The ECB tended to orient its allotment decisions towards ensuring an average interbank overnight rate close to the tender rate." 
liquidity injection prior to the tender.

The intuition for these results is the following. When the loss function is asymmetric, the central bank is more concerned about letting the interbank rate fall below the target, and for this reason it supplies less liquidity than the one required to keep the average interbank rate equal to the target rate. In fixed rate tenders, the differential between the average interbank rate and rate at which the liquidity is provided generates an expected profit for the banks which is increasing in the quantity allotted. Hence, they have an incentive to increase the size of their bid. In contrast, in variable rate tenders, the banks fully compensate this differential by offering higher rates, so in equilibrium they will be indifferent as to the amount bid (as long as it exceeds the central bank's desired liquidity injection). On the other hand, when the loss function of the central bank is symmetric, the average interbank rate will be equal to the target rate, and fixed and variable rate tenders will have the same outcomes.

In order to address the issue of whether overbidding is a problem, we extend the model to the case where the banks differ in the amount of collateral available for borrowing from the central bank. In this case we show that, in fixed rate tenders, when the loss function of the central bank is asymmetric, the high collateral banks will get a higher payoff than the low collateral banks. To the extent that different banking practices in the various countries of the euro zone imply that banks with similar balance sheets may have very different levels of collateralizable assets, ${ }^{4}$ we conclude that fixed rate tenders may lead to unequal treatment of banks by the ECB It is important to stress that with a perfectly competitive interbank market, liquidity can be redistributed across the area at no cost, so this would not be a problem of efficiency but a problem of distribution (of rents from the ECB to the banks).

Given the difference in the outcomes under symmetry or asymmetry of the loss function of the central bank, we use data from the 76 fixed rate tenders conducted during the period January 1999 - June 2000 to estimate the asymmetry parameter of the loss function of the ECB. The results indicate that this parameter is significantly different from zero, which is consistent with the extreme overbidding behavior of

\footnotetext{
${ }^{4} \mathrm{~A}$ distinction is made between two categories of collateral. Tier one assets consists of marketable debt instruments fulfilling uniform euro area-wide eligibility criteria specified by the ECB. Tier two consists of additional assets, marketable and non-marketable, which are of particular importance for national financial markets and banking systems and for which eligibility criteria are established by the national central banks, subject to ECB approval. See ECB (1998, Chapter 6).
} 
the banks in these tenders. In addition, the switch to variable rate tenders that took place in June 2000 provides a natural experiment to test our theoretical model. We show that the evidence on the behavior of the marginal interest rate of the 9 American auctions conducted during the period June - August 2000 is in line with the predictions of the model.

The closest reference to our work is the paper by Nautz and Oechssler (1999). They construct a model of strategic bidding in fuxed rate tenders in which there is no interbank market and the banks minimize a quadratic loss function in the deviations between the liquidity allotted by the central bank and the liquidity required by them. Their main result is that the fixed rate tender game does not have an equilibrium. Catalāo Lopes (2000) compares the performance of fixed and variable rate tenders in the context of a model with an interbank market. She shows that switching from the former to the latter ameliorates the overbidding problem. PérezQuirós and Rodríguez-Mendizábal (2000) propose a model of the behavior of the interbank rate over the reserve maintenance period that tries to explain the evidence for Germany before and after the adoption of the euro. Finally, Bindseil (2000) focuses on whether the central bank should announce its forecast of the autonomous liquidity creation factors before the tender.

The paper is organized as follows. Section 2 presents the model. Sections 3 and 4 analyze the equilibrium of fixed and variable rate tenders, respectively. Section 5 extends the previous results to the case where the banks differ in the amount of collateral. Section 6 contains our empirical estimation of the asymmetry parameter of the loss function of the ECB. Section 7 offers a some concluding remarks. Appendix A presents a simple model of the interbank market that is used to motivate the equilibrium interest rate equation that appears in the text, and Appendix B contains the proofs of all the results.

\section{The Model}

Consider a model with two dates $(t=0,1)$ and two types of agents: a central bank, and a continuum of measure one of identical risk neutral private banks. At date 0 the central bank provides an amount of liquidity $l$ using one of several possible tender 
procedures to be described in detail below. At date 1 there is an interbank market where the private banks can trade their excess liquidity at an interest rate $r$.

The equilibrium interest rate in the interbank market is given by

$$
r=\alpha-\beta l+\varepsilon,
$$

where $\alpha$ and $\beta$ are positive coefficients, and $\varepsilon$ is a random disturbance with zero mean. Equation (1) has two main features. First, the equilibrium interbank rate depends negatively on the liquidity $l$ provided by the central bank at date 0 . Second, it is subject to random shocks. Both features are rationalized in the model of the interbank market presented in Appendix A. ${ }^{5}$

At date 0 the central bank observes a signal $\eta$ which is correlated with the liquidity shock $\varepsilon$. Specifically. we assume that

$$
\varepsilon=\eta+u
$$

where $\eta$ and $u$ are independent random variables with zero mean, so $E(\varepsilon \mid \eta)=\eta$. We also assume that $\eta$ has a compact support $[\eta, \bar{\eta}]$, and we let $F(u)$ denote the cumulative distribution function of $u$.

The interpretation of these shocks is as follows: $\varepsilon$ captures the effect on the equilibrium interbank rate of autonomous liquidity creation and absorption factors (like changes in cash holdings, net government deposits with the central bank, etc.), while $\eta$ captures the estimate that the central bank has on this effect based on its forecast of these factors, and $u$ is the error term.

The central bank wants to steer the equilibrium interbank rate $r$ towards a target rate $\widehat{r}$ that characterizes the stance of monetary policy. If the liquidity injection were done at date 1 , the central bank could effectively ensure that $r=\widehat{r}$ by setting

$$
l=\frac{\alpha-\widehat{r}+\varepsilon}{\beta} .
$$

\footnotetext{
${ }^{5}$ In this model the representative bank is subject to a reserve requirement that has to be fulfilled on average over a two-date maintenance period. The averaging provision means that bank reserves held on any date are perfect substitutes for the purpose of satisfying the requirement. As noted by Campbell (1987) and Hamilton (1996) among others, this implies that interbank rates follow a martingale. Moreover, the equilibrium interbank rate at the first date of the maintenance period will be a weighted average of the interest rates of the marginal lending and deposit facilities, with weights that are, respectively, decreasing and increasing in the liquidity initially provided by the central bank.
} 
This corresponds to the procedure used by the Federal Reserve System in its open market operations. ${ }^{6}$

However, in our framework the central bank has to decide on $l$ before the liquidity shock $\varepsilon$ is realized, so the equilibrium interbank rate $r$ will in general differ from the target rate $\widehat{r}$. In setting the liquidity injection $l$ at date 0 we will assume that the central bank minimizes the conditional expected value of a loss function that depends on the quadratic difference between the interbank rate $r$ and the target rate $\widehat{r}$. Specifically, we assurne the following objective function

$$
E\left[(r-\widehat{r})^{2}+\gamma 1_{[r<\widehat{r}]}(r-\widehat{r})^{2} \mid \eta\right],
$$

where $1_{[r<7]}$ is an indicator function that takes the value 1 when $r<\widehat{r}$. Although the parameter $\gamma$ could in principle be negative, we will restrict attention to the case $\gamma \geq 0$. If $\gamma>0$ the central bank loss function is asymmetric, with interbank rates below the target $\widehat{r}$ penalized more heavily than rates above the target. If $\gamma=0$ the loss function is symmetric.

Given this objective function, the following result characterizes the desired liquidity injection of the central bank.

Lemma 1 The central bank desired liquidity injection is described by the function

$$
s_{\gamma}(\eta)=\frac{\alpha-r_{\gamma}+\eta}{\beta}
$$

where $r_{\gamma}$ is increasing in $\gamma$ with $r_{0}=\widehat{r}$.

The liquidity supply function $s_{\gamma}(\eta)$ is linearly increasing in the signal $\eta$. This means that when the central bank will want to inject more liquidity when it anticipates tight conditions in the interbank market (i.e. observes a high $\eta$ ). On the other hand, for $\gamma>0$ we have $r_{\gamma}>r_{0}=\widehat{r}$, so a central bank with an asymmetric loss function will want to provide, ceteris paribus, less liquidity than a central bank with a symmetric loss function.

Substituting the function $s_{\gamma}(\eta)$ into the interest rate equation (1), and taking into account the definition of $u$ in (2), gives

$$
r=r_{\gamma}+u,
$$

\footnotetext{
${ }^{6}$ It should be noted that, although feasible, this type of fine-tuning operations are not usually executed by the ECB.
} 
which implies $E(r \mid \eta)=r_{\gamma}$. Hence a central bank with a symmetric loss function will try to achieve an interbank rate that, on average, is equal to the target rate $\widehat{r}$, while a central bank with an asymunetric loss function will aim at higher average interbank rates. These implications of Lemma 1 will be useful to provide intuition for the results in the following sections.

\section{Equilibrium Analysis of Fixed Rate Tenders}

Suppose that at date 0 the central bank provides liquidity to the banks through a fixed rate tender. In this procedure the representative bank submits a bid $b$ and receives an allotment $l$ at the target interest rate $\hat{r}$, which is announced by the central bank prior to the tender.

To begin with we shall assume that the bid $b$ cannot exceed the amount of collateral $c$ that the bank holds, so $b \in[0, c]$. We also assume that the minimum desired liquidity injection (that is, the one that corresponds to the lowest signal $\underline{\eta}$ ) is positive, so

$$
s_{\gamma}(\underline{\eta})>0
$$

and that the representative bank has sufficient collateral to cover the maximum desired liquidity injection (that is, the one that corresponds to the highest signal $\bar{\eta}$ ), so

$$
s_{\gamma}(\bar{\eta})<c .
$$

If $s$ denotes the liquidity that the central bank decides to provide, and $b^{*}$ is the total amount bid then

$$
l=\min \left\{b, \frac{s}{b^{*}} b\right\} .
$$

According to this expression, the bank gets the amount $b$ it bid unless the total amount bid $b^{*}$ exceeds the amount $s$ that the central bank wants to inject, in which case the bank gets the fraction $s / b^{*}$ of the amount bid $b$.

The tender procedure is modeled as a noncooperative game between the central bank and the representative bank. The game is sequential: the central bank decides on $s$ after observing the total amount bid $b^{*}$. Moreover, we assume that the representative bank knows the loss function of the central bank (in particular, the value of the 
asymmetry parameter $\gamma$ ), but it does not observe (nor the central bank reveals) the value of the signal $\eta$ on the liquidity conditions in the interbank market at date 1 .

In a symmetric equilibrium it must be the case that $b=b^{*}$, so the central bank provides an amount of liquidity equal to

$$
l=\min \left\{b^{*}, s\right\} .
$$

Substituting this expression into the interest rate equation (1), gives the following equilibrium interbank rate

$$
r=\alpha-\beta \min \left\{b^{*}, s\right\}+\varepsilon
$$

The next result characterizes the dominant strategy of the central bank in the fixed rate tender game.

Lemma 2 In the fixed rate tender the central bank will choose $s=s_{\gamma}(\eta)$.

The reason why $s=s_{\gamma}(\eta)$ is a dominant strategy is easy to explain. In deciding on its provision of liquidity, the central bank has to take into account the constraint that the liquidity injection $l$ cannot exceed the total amount bid $b^{*}$. If this constraint is not binding, by Lemma 1 we have $s=s_{\gamma}(\eta)$. On the other hand, if this constraint is binding (that is, if $s_{\gamma}(\eta)>b^{*}$ ), since the central bank's objective function is continuous in $s$, strictly convex for $s<b^{*}$, and constant for $s \geq b^{*}$, it is clear that any $s \geq b^{*}$ will be optimal, so we can take $s=s_{\gamma}(\eta)$.

The representative bank chooses its bid $b \in[0, c]$ in order to maximize

$$
E[l(r-\widehat{r})]
$$

That is, the bank maximizes the expected return obtained by placing in the interbank market at the interest rate $r$ the quantity $l$ allotted by the central bank at the rate $\hat{r}$. This objective function is justified in the model of the interbank market presented in Appendix A.

The following result characterizes the equilibrium of the fixed rate tender.

Proposition 1 In the fixed rate tender, when the loss function of the central bank is asymmetric $(\gamma>0)$ there is a unique equilibrium in which the representative bank 
bids $b=c$, whereas when the loss function is symmetric $(\gamma=0)$ any bid $b \in\left[s_{0}(\bar{\eta}), c\right]$ constitutes an equilibrium. In either case, the central bank provides an amount of liquidity equal to $s_{\gamma}(\eta)$, and the expected equilibrium interbank rate is $r_{\gamma}$.

To explain the intuition for this result notice that, when $\gamma>0$, the equilibrium interest rate equation (10) together Lemma 1 implies that for any $b^{*}$ we have

$$
E(r)=E\left[\alpha-\beta \min \left\{b^{*}, s_{\gamma}(\eta)\right\}+\varepsilon\right] \geq E\left[\alpha-\beta s_{\gamma}(\eta)+\eta+u\right]=r_{\gamma}>\widehat{r} .
$$

Hence when the loss function of the central bank is asymmetric, the expected equilibrium interbank rate will always be above the interest rate $\widehat{r}$ at which the central bank allocates funds in the tender. Since the quantity allotted to the representative bank is an increasing function of its bid, it follows that the bank has an incentive to bid the maximum amount $c$.

On the other hand, when $\gamma=0$, the equilibrium interest rate equation (10) together with Lemma 1 implies

$$
E(r)=E\left[\alpha-\beta \min \left\{b^{*}, s_{\mathbf{0}}(\eta)\right\}+\varepsilon\right] \geq E\left[\alpha-\beta s_{0}(\eta)+\eta+u\right]=r_{0}=\widehat{r},
$$

with strict inequality for (high) realizations of $\eta$ for which $b^{*}<s_{0}(\eta)$. Hence if $b^{*}<$ $s_{0}(\bar{\eta})$ we have $E(r)>\widehat{r}$, so the representative bank has an incentive to bid the maximum amount $c$, which contradicts the assumption $b^{*}<s_{0}(\bar{\eta})<c$. Therefore we must have $b^{*} \geq s_{0}(\bar{\eta})$, in which case $E(r)=\widehat{r}$, the payoff of the representative bank is always zero, and $b=b^{*}$ is an equilibrium bid.

The preceding discussion can be summarized as follows: Proposition 1 implies that, on average, the equilibrium interbank rate $r$ will be above the central bank target rate $\widehat{r}$ if and only if the loss function of the central bank is asymmetric. Hence when $\gamma>0$ there is a unique equilibrium characterized by extreme overbidding, whereas when $\gamma=0$ there is a continuum of equilibria such that the total amount bid is greater than or equal to the central bank's maximum liquidity injection. ${ }^{7}$

We next analyze what would happen if prior to the tender the central bank reveals its information $\eta$ (or, equivalently, announces its desired liquidity injection $\left.s_{\gamma}(\eta)\right)^{8}$

\footnotetext{
${ }^{7}$ Thus the equilibrium correspondence jumps discontinuously at the point $\gamma=0$

${ }^{8}$ Observe that since the function $s_{\gamma}(\eta)$ is increasing and the representative bank knows the parameter $\gamma$, then learning the value of $s_{\gamma}(\eta)$ is equivalent to leaming $\eta$.
} 
The sequence of moves in the game between the central bank and the representative bank is now reversed, with the central bank moving first.

Proposition 2 If in the fixed rate tender the central bank preannounces the liquidity $s_{\gamma}(\eta)$ it intends to provide, there is no change in the equilibrium bid when the loss function of the central bank is asymmetric $(\gamma>0)$, whereas when the loss function is symmetric $(\gamma=0)$ any bid $b \in\left[s_{0}(\eta), c\right]$ constitutes an equilibrium. In either case, the central bank provides an amount of liquidity equal to $s_{\gamma}(\eta)$, and the expected equilibrium interbank rate is $r_{\gamma}$.

The intuition for this result is easy to explain. When $\gamma>0$ the announcement has no effect on the equilibrium bid, since as noted above, for any $b^{*}$, the expected equilibrium interbank rate will always be above the interest rate $\hat{r}$ at which the central bank allocates funds in the tender. Hence the representative bank has an incentive to bid the maximum amount $c$. On the other hand, when $\gamma=0$ we have $E(r)>\widehat{r}$ if and only if $b^{*}<s_{0}(\eta)$, so we now rule out equilibrium bids below $s_{0}(\eta)$.

Up until now, we have assumed that the bid $b$ submitted by the representative bank cannot exceed its collateral $c$. The results when the bank is allowed to bid any $b \in[0, \bar{b}]$, with $\bar{b}>c$, are easy to derive using the same arguments as in the proofs of Propositions 1 and 2 . When the central bank does not announce its desired liquidity injection, the equilibrium bid will be $\bar{b}$, if $\gamma>0$, and any $b \in\left[s_{0}(\bar{\eta}), \bar{b}\right]$, if $\gamma=0$. And when the central bank announces $s_{\gamma}(\eta)$ prior to the tender, the equilibrium bid will be $\bar{b}$, if $\gamma>0$, and any $b \in\left[s_{0}(\eta), \bar{b}\right]$, if $\gamma=0$. Finally, there will be no equilibrium when $\gamma>0$ and $\bar{b}=\infty$.

The case $\bar{b}=\infty$ is relevant in the light of the statement of the ECB of 2 February 1999 clarifying that "...the valid interpretation of the General Documentation allows tender bids not actually covered by collateral at the time of submission of the bids, and just requires the financial capacity to have the collateral on the date of settlement of the tender." For this reason, the nonexistence of equilibrium for $\gamma>0$ deserves further analysis. Nautz and Oechssler (1999) get the same result, and then propose a myopic adjustment process that generates an increasing sequence of bids. However, this process implicitly assumes some bounded rationality on the part of the banks which does not seem very plausible (at least after the initial learning is completed). An aiternative approach would be to modify the model in order to get back existence. 
For example, one could introduce penalties for "excessive bidding." Such penalties are in fact contemplated in the ECB's General Documentation (1998, p.30) that "...provides for the possibility to check underlying assets available to counterparties in order to detect cases of excessive bidding and to impose penalties if such excessive bidding is evidenced." 9 Exploring in detail this alternative is left for future work

The results in this section indicate that overbidding by the banks in the fixed rate tender is explained by the asymmetry of the loss function of the central bank, specifically its reluctance to see interbank interest rates fall below the target rate $\widehat{r}$. In this case the central bank supplies less liquidity than that needed to ensure that $E(r)=\widehat{r}$, so it is rational for the banks to bid the maximum possible amount; and if there is no such upper bound (or there are no penalties for "excessive bidding"), an equilibrium does not exist. On the other hand, if the loss function of the central bank is symmetric, there is a continuum of equilibria in which the banks are always rationed, unless the central bank preannounces its desired liquidity injection, in which case there is also an equilibrium without overbidding (that is with $b^{*}=s_{0}(\eta)$ ).

\section{Equilibrium Analysis of Variable Rate Tenders}

In variable rate tenders, the representative bank bids an amount $b$ at an interest rate $\widetilde{r}$. The central bank orders the bids according to the interest rate offered, and successively lower interest rates are accepted until the total liquidity to be allotted is exhausted. In the single rate (or uniform or "Dutch") auction the interest rate applied for all satisfied bids is the marginal interest rate (the lowest interest rate accepted). In the multiple rate (or discriminatory or "American") auction the interest rate applied is the rate offered for each accepted bid.

In variable rate tenders the behavior of the central bank is identical to the one described in the previous section, namely it chooses to supply the amount of liquidity $s_{\gamma}(\eta)$. This follows from the assumption that the central bank only cares about the deviations of the equilibrium interbank rate $r$ from the target rate $\widehat{r}$, and not about the marginal (or the average) rate applied to successful bids in the tender.

\footnotetext{
9 "Excessive bidding is considered to have taken place if the counterparty could not possibly have delivered sufficient underlying assets to cover its tender bid, when taking account of its holdings of securities and its borrowing potential" (ECB, 1998, p.30).
} 
We next examine the equilibrium outcome of the two types of auction.

\subsection{The Dutch Auction}

In the Dutch auction the representative bank chooses its bid $b \in[0, c]$ and offered interest rate $\tilde{r}$ in order to maximize

$$
E[l(s)(r-\tilde{r}(s))]
$$

where

$$
\begin{gathered}
l(s)=\left\{\begin{array}{cc}
b, & \text { if either } \widetilde{r}>\widetilde{r}^{*}, \text { or } \tilde{r}<\widetilde{r}^{*} \text { and } s>b^{*} \\
\min \left\{b, \frac{s}{b^{*}} b\right\}, & \text { if } \tilde{r}=\widetilde{r}^{*} \\
0, & \text { if } \tilde{r}<\widetilde{r}^{*} \text { and } s \leq b^{*}
\end{array}\right. \\
\widetilde{r}(s)=\left\{\begin{array}{cc}
\widetilde{r}, & \text { if } \tilde{r}<\widetilde{r}^{*} \text { and } s>b^{*} \\
\widetilde{r}^{*}, & \text { otherwise }
\end{array}\right.
\end{gathered}
$$

and $b^{*}$ and $\tilde{r}^{*}$ denote, respectively, the amount bid and the interest rate offered by all the other banks (assuming a symmetric equilibrium).

In words, the representative bank gets the amount bid $b$ if it offers an interest rate $\vec{r}$ higher than the interest rate $\widetilde{r}^{*}$ offered by the other banks, or if $\tilde{r}<\widetilde{r}^{*}$ and $\tilde{r}$ happens to be the marginal interest rate in the auction. It gets

$$
\min \left\{b, \frac{s}{b^{*}} b\right\}
$$

if it offers $\widetilde{r}=\widetilde{r}^{*}$. Finally, it gets 0 if it offers $\tilde{r}<\widetilde{r}^{*}$ and $\widetilde{r}^{*}$ is the marginal interest rate of the auction. Notice that when $\tilde{r}=\widetilde{r}^{*}$ (which will obtain in a symmetric equilibrium) the only difference between this objective function and the one in the previous section is the fact that now the bank pays the marginal interest rate $\widehat{r}^{*}$, instead of the target rate $\widehat{r}$, for the quantity allotted.

It is important to stress that in the analysis that follows the representative bank is assumed to know both the interest rate $\widehat{r}$ that characterizes the stance of monetary policy, and the value of the parameter $\gamma$ that characterizes the loss function of the central bank. Obviously, this raises the issue of how the central bank may signal the rate $\hat{r}$. We will come back to this issue at the end of this section.

The next result characterizes the symmetric equilibrium of the Dutch auction. 
Proposition 3 In the Dutch auction, any bid $b \in\left[s_{\gamma}(\bar{\eta}), c\right]$ at the interest rate $\tilde{r}=r_{\gamma}$ constitutes an equilibrium in which the central bank provides an amount of liquidity equal to $s_{\gamma}(\eta)$, and the expected equilibrium interbank rate is $r_{\gamma}$.

Proposition 3 shows that when the loss function of the central bank is symmetric the outcome of the Dutch auction is the same as the outcome of the fixed rate tender: the banks bid a sufficiently large amount (that implies that they are always going to be rationed) at the rate $r_{0}=\widehat{r}$ (which is the expected equilibrium interbank rate). On the other hand, when the loss function is asymmetric there is no longer a unique equilibrium at the corner with maximum bids, but a continuum of equilibria in which the banks bid a sufficiently large amount at the rate $r_{\gamma}$ (which is now the expected equilibrium interbank rate).

Thus in the Dutch auction the nature of equilibrium is the same for all $\gamma \geq 0$. The reason for this result is that the banks correct for the bias in the loss function of the central bank by offering an interest rate that equals the expected equilibrium interbank rate and for which their payoff is always zero.

We next analyze what happens when the central bank reveals $\eta$ (or, equivalently, announces its desired liquidity injection $\left.s_{\gamma}(\eta)\right)$ prior to the tender.

Proposition 4 If in the Dutch auction the central bank preannounces the liquidity $s_{\gamma}(\eta)$ it intends to provide, any bid $b \in\left[s_{\gamma}(\eta), c\right]$ at the interest rate $r_{\gamma}$ constitutes an equilibrium in which the central bank provides an amount of liquidity equal to $s_{\gamma}(\eta)$, and the expected equilibrium interbank rate is $r_{\cdot y}$.

The only difference between this result and Proposition 3 is that now the range of equilibrium bids is $\left[s_{\gamma}(\eta), c\right]$, rather than $\left[s_{\gamma}(\bar{\eta}), c\right]$, so there is always an equilibrium without overbidding. Moreover, one can argue that the announcement of intended liquidity injection by the central bank may serve as coordination device for the banks in the presence of multiple equilibria, in which case the equilibrium in which the banks bid $b=s_{\gamma}(\eta)$ may actually obtain.

Finally, in the case where the representative bank is allowed to bid any $b \in[0, \bar{b}]$, with $\bar{b}>c$, it is easy to derive that, for any $\gamma \geq 0$, any bid $b \in\left[s_{\gamma}(\bar{\gamma}), \bar{b}\right]$ (or any $b \in\left[s_{\gamma}(\eta), \bar{b}\right]$ when the central bank reveals $\eta$ ) at the interest rate $r_{\gamma}$ constitutes an equilibrium. Thus even when $\vec{b}=\infty$ an equilibrium always exists. 


\subsection{The American Auction}

In the American auction the representative bank chooses its bid $b \in[0, c]$ and offered interest rate $\tilde{r}$ in order to maximize

$$
E[l(s)(r-\widetilde{r})],
$$

where $l(s)$ is given by (12).

The American auction is the same as the Dutch auction except that now the bank always pays the interest rate $\tilde{T}$ offered, instead of the marginal interest rate of the auction $\tilde{r}(s)$. Despite this difference, following the arguments in the proofs of Propositions 3 and 4 one can show that the equilibrium outcomes of the American auction are the same as those of the Dutch auction. Hence the representative bank will bid any $b \in\left[s_{\gamma}(\bar{\eta}), c\right]$ (or any $b \in\left[s_{\gamma}(\eta), c\right]$ when the central bank reveals $\eta$ ) at the interest rate $\tilde{r}=r_{\gamma}$, and its equilibrium payoff will be zero. ${ }^{10}$

A concern that arises in the case of variable rate tenders is how the central bank may signal the stance of monetary policy. In fixed rate tenders, this is achieved by the announcement of the interest rate $\widehat{r}$ at which the liquidity allotted is going to provided. In variable rate tenders the marginal interest rate is endogenously determined, so this signal is no longer available. In its decision of June 2000 to switch from fixed to variable rate tenders in the main refinancing operations, the ECB addressed this problem by introducing a minimum bid rate, and stating that "for the purpose of signalling the monetary policy stance, the minimum bid is designed to play the role performed, until now, by the rate in fixed rate tenders." In the context of our model one can check that the constraint that the interest rates offered by the banks be greater than or equal to the target rate $\hat{r}$ does not alter any of the arguments in the proofs of Propositions 3 and 4, so we have exactly the same characterization of equilibria.

A second concern is whether the volatility of the interbank rate would be higher with variable rate tenders. But as long as the central bank can signal effectively the target rate $\widehat{r}$, equation (5) together with Propositions 1-4 imply that $\operatorname{Var}(r)=$

\footnotetext{
${ }^{10}$ Notice that if the bank offers a lower rate $\tilde{r}<r_{\gamma}$ its payoff will be zero (since $l(s)=0$ ), while and if it offers a higher rate $\tilde{r}>r_{\gamma}$ its payoff will be negative (since $E[l(s)(r-\tilde{r})]=b\left(r_{\gamma}-\tilde{r}\right)<0$ ), so these deviations are not profitable.
} 
$\operatorname{Var}(u)$ regardless of the type of tender and regardless of whether the central bank preannounces its intended liquidity injection.

The results in this section show that if the loss function of the central bank is asymmetric, and as long as the central bank can signal effectively the stance of monetary policy, switching to variable rate tenders makes it possible achieve equilibria with moderate overbidding at no cost in terms of the volatility of the interbank rate. Moreover, in the case where the central bank preannounces its desired liquidity injection an equilibrium without overbidding may be selected by the banks.

\section{The Model with Heterogeneous Banks}

This section extends our previous results to the case where the banks differ in the amount of collateral that they hold for borrowing from the central bank. Specifically, we postulate a cumulative distribution function of collateral, $H(c)$, with support $[0, \bar{c}]$, and consider the equilibrium of the fixed and variable rate tenders.

In this setup, assumption (7) is replaced by the following assumption

$$
s_{\gamma}(\bar{\eta})<\int_{0}^{\bar{c}} c d H(c)
$$

that guarantees that the banks have an aggregate amount of collateral that is greater than the central bank's maximum liquidity injection.

The strategy of a bank with collateral $c$ in the fixed rate tender is given by a function $b(c)$ that describes the amount bid as a function of its collateral. Two cases will be considered. In the first case we require $b(c) \in[0, c]$, while in the second we let $b(c) \in[0, \bar{b}]$, with $\bar{b}>\bar{c}$, but require the bank to have enough collateral to cover the allotted amount. ${ }^{11}$ Similarly, in variable rate tenders the strategy of a bank with collateral $c$ is a pair $(b(c), \widetilde{r}(c))$ that describes the amount bid and the interest rate offered as a function of its collateral. As in fixed rate tenders, we will consider the cases $b(c) \in[0, c]$ and $b(c) \in[0, \bar{b}]$.

The following result characterizes the equilibrium of fixed rate tenders.

Proposition 5 In the fixed rate tender with $b(c) \in[0, c]$, when the loss function of the central bank is asymmetric $(\gamma>0)$ there is a unique equilibrium with $b(c)=c$,

\footnotetext{
${ }^{11}$ As noted in Section 3, this is what the ECB requires.
} 
whereas when the loss function is symmetric $(\gamma=0)$ any feasible function $b(c)$ such that $\int_{0}^{\bar{c}} b(c) d H(c) \geq s_{\gamma}(\bar{\eta})$ constitutes an equilibrium. On the other hand, in the fixed rate tender with $b(c) \in[0, \bar{b}]$, when $\gamma>0$ there is a unique equilibrium implicitly described by

$$
b(c)=\min \left\{\frac{b^{*} c}{s_{\gamma}(\bar{\eta})}, \bar{b}\right\},
$$

where $b^{*}=\int_{0}^{\bar{c}} b(c) d H(c)$, whereas when $\gamma=0$ any function $b(c)$ such that

$$
b(c) \leq \min \left\{\frac{b^{*} c}{s_{\gamma}(\bar{\eta})}, \bar{b}\right\},
$$

where $b^{*}=\int_{0}^{\bar{c}} b(c) d H(c) \geq s_{\gamma}(\bar{\eta})$, constitutes an equilibrium. In any of these cases, the central bank provides an amount of liquidity equal to $s_{\gamma}(\eta)$, and the expected equilibrium interbank rate is $r_{\gamma}$.

Thus when the loss function of the central bank is asymmetric, the banks bid the maximum amount compatible with satisfying the collateral requirement with probability one. If $b(c)$ is constrained to belong to the interval $[0, c]$ they bid their collateral $c$, while if $b(c)$ inay belong to $[0, \bar{b}]$ they bid either the maximum amount $\bar{b}$ or the maximum amount that ensures that the collateral requirement

$$
\frac{s_{\gamma}(\eta)}{b^{*}} b(c) \leq c,
$$

is satisfied for all $\eta \in[\eta, \bar{\eta}]$, which gives (15). In both cases the equilibrium payoff of a bank with collateral $c$ is given by

$$
\frac{E\left[s_{\gamma}(\eta)\right]}{b^{*}} b(c)\left(r_{\gamma}-\widehat{r}\right) .
$$

Since the function $b(c)$ is non decreasing and $r_{\gamma}-\widehat{r}>0$, it follows that the high collateral banks get a higher payoff than the low collateral banks. On the other hand, when the loss function is symmetric, there are multiple equilibria in which all the banks get a zero payoff.

A simple numerical example will serve to illustrate these results. Suppose that the loss function of the central bank is asymmetric $(\gamma>0)$ and that collateral is uniformly distributed in the interval $[0,1]$. Then in the case $b(c) \in[0, c]$ the banks bid $b(c)=c$, while in the case $b(c) \in[0, \bar{b}]$ (and assuming that $s_{\gamma}(\bar{\eta})=1 / 3$ so (14) is satisfied) 
one can check that the banks bid $b(c)=\min \left\{3 b^{*} c, \bar{b}\right\}$ with $b^{*}=\bar{b}(3+\sqrt{3}) / 6^{12}$ Since $\gamma>0$ implies that the expected equilibrium interbank rate $r_{\gamma}$ will be greater than the tender rate $\hat{r}$, the central bank will be effectively transferring rents to the banks in proportion to their bids. The distributional implications of the two alternative cases are shown in Table 1. The example illustrates how banks with higher collateral get a higher proportion of these rents, and how the distribution becomes more uneven when the banks can only bid up to their collateral. ${ }^{13}$

Table 1 Share of rents going to banks in different quartiles of the distribution of collateral.

\begin{tabular}{|c|c|c|c|c|}
\cline { 2 - 5 } \multicolumn{1}{c|}{} & 1st quartile & 2nd quartile & 3rd quartile & 4th quartile \\
\hline$b(c) \in[0, c]$ & $6.25 \%$ & $18.75 \%$ & $31.25 \%$ & $43.75 \%$ \\
\hline$b(c) \in[0, \bar{b}]$ & $9.38 \%$ & $27.23 \%$ & $31.70 \%$ & $31.70 \%$ \\
\hline
\end{tabular}

It is important to note that to the extent that different banking practices and traditions in the various countries of the euro zone imply that banks with similar balance sheets but located in different countries may have different $c$ 's, and provided that the loss function of the ECB is asymmetric, the fixed rate tender procedure implies unequal treatment of banks. In particular, those banks located in countries with a higher structural level of collateral will get a higher share of the total rents that the ECB hands over by keeping the average interbank rate above the tender rate $\widehat{r}$.

We next consider what happens when the central bank uses variable rate tenders.

Proposition 6 In variable rate tenders with $b(c) \in[0, c]$, any feasible function $b(c)$ such that $\int_{0}^{\bar{c}} b(c) d H(c) \geq s_{\gamma}(\bar{\eta})$, together with the function $\widetilde{r}(c)=r_{\gamma}$, constitutes an equilibrium. On the other hand, in variable rate tenders with $b(c) \in[0, \bar{b}]$, any function $b(c)$ such that

$$
b(c) \leq \min \left\{\frac{b^{*} c}{s_{\gamma}(\bar{\eta})}, \bar{b}\right\}
$$

\footnotetext{
${ }^{12}$ In this latter case the banks with collateral $c \leq \bar{b} / 3 b^{*} \simeq 42$ bid an amount $b(c)=3 b^{*} c$ which is linearly increasing in $c$, whereas the banks with $c \geq \bar{b} / 3 b^{*}$ bid the maximum amount $b(c)=\bar{b}$.

${ }^{13}$ It is worth noting that the second distribution does not depend on the upper limit $\bar{b}$. This is a general result that follows from the fact that the equilibrium bid $b(c)$ is proportional to $\vec{b}$.
} 
where $b^{*}=\int_{0}^{\bar{c}} b(c) d H(c) \geq s_{\gamma}(\bar{\eta})$, together with the function $\widetilde{r}(c)=r_{\gamma}$, constitutes an equilibrium. In either case, the central bank provides an amount of liquidity equal to $s_{\gamma}(\eta)$, and the expected equilibrium interbank rate is $r_{\gamma}$.

As in the model with identical banks, the nature of equilibrium is the same for all $\gamma \geq 0$. The bids of the banks may now be different, but they all offer the same interest rate $r_{\gamma}$, which is the expected equilibrium interbank rate for the value of $\gamma$ that characterizes the loss function of the central bank, so their payoff is always equal to zero.

Hence we have shown that using fixed rate tenders when the loss function of the central bank is asymmetric may lead to unequal treatment of the banks, and that this problem disappears under variable rate tenders.

\section{Is the Loss Function of the ECB Asymmetric?}

In previous sections we have shown that the equilibrium outcome of fixed rate tenders critically depends on the symunetry or asymmetry of the loss function of the central bank. In this section we use data for the period 4 January 1999 - 27 June 2000 in which the ECB conducted 76 fixed rate tenders to test whether the parameter $\gamma$ of its loss function is significantly different from zero. In addition, we use data for the period 28 June - 23 August 2000 in which the ECB conducted 9 variable rate tenders to get some preliminary evidence on the predictions of our model.

Since a symmetric loss function implies that, for fixed rate tenders, the differential between the interbank rate $r$ and the tender rate $\widehat{r}$ will on average be zero, an indirect and simple way of testing the null hypothesis $\gamma=0$ is to test whether

$$
\mu=E(r)-\widehat{r}=r_{\gamma}-\widehat{r}=0 .
$$

The results for the period January 1999 - June 2000 are shown in Table 2a. In this table the tender rate $\widehat{r}$ is the interest rate of the main refinancing operations of the $\mathrm{ECB}$, and two alternative measures of the interbank rate $r$ are considered: the 1-week euro interbank offered rate (Euribor-7) and the euro overnight interest rate (Eonia). ${ }^{14}$

\footnotetext{
${ }^{14}$ Euribor is the rate at which a prime bank is willing to lend funds in euro to another prime bank, and is computed as the average of the daily offer rates of a representative panel of prime
} 
It is worth noting that when comparing the interest rates on interbank deposits with the rate of the main refinancing operations there are two potential biases that might affect the spread $r-\hat{r}$. First, differences in credit risk: The main refinancing operations are collateralized while interbank deposits are unsecured, which may bias the spread upwards. Second, differences in maturity: The interest rate on the main refinancing operations has a positive term premium when compared to rates on less-than-twoweek deposits, which may bias the spread downwards. ${ }^{15}$ In the case of Euribor-7, the difference in maturity is only one week and credit risk is likely to be very small (since it is a rate offered to prime banks), so the two biases are probably negligible. On the other hand, Eonia might be subject to higher biases, pointing in opposite directions so their net effect is difficult to evaluate, but it is the interest rate corresponding to the most active segment of the interbank market.

To check the robustness of the results three alternative samples have been considered for the Eonia rate: a sample including only the days of settlement of the tender (with $n=76$ observations), a second sample including all days except those corresponding to the end of the monthly maintenance periods of the reserve requirement (with $n=367$ ), and finally the whole sample (with $n=385$ ). ${ }^{16}$ In each case, the point estimate $\widehat{\mu}$, its standard error, the $p$-value of the one-sided test of the null hypothesis $\mu=0$ (against the alternative $\mu>0$ ), and the sample size are reported.

Table 2a Estimation of $\mu=E(r)-\widehat{r}$ for the period January 1999 - June 2000.

\begin{tabular}{|c|c|c|c|c|}
\cline { 2 - 5 } \multicolumn{1}{c|}{} & $r=$ Euribor-7 & $r=$ Eonia & $r=$ Eonia & $r=$ Eonia \\
\hline$\widehat{\mu}$ & .13 & .08 & .08 & .07 \\
$(s . e)$. & $(.02)$ & $(.02)$ & $(.01)$ & $(.01)$ \\
{$[p$-value $]$} & {$[.00]$} & {$[.00]$} & {$[.00]$} & {$[.00]$} \\
$n$ & 76 & 76 & 367 & 385 \\
\hline
\end{tabular}

\footnotetext{
banks. Eonia is an effective overnight rate computed as a weighted average of the interest rates on unsecured overnight contracts on deposits denominated in euro reported by a panel of contributing banks.

${ }^{15}$ Unfortunately, the market for two-week deposits is not active enough as to offer reliable interest rates.

${ }^{16}$ We have not used these three samples with the Euribor due to the overlapping nature of the data.
} 
The four columns of Table $2 \mathrm{a}$ convey the same qualitative result: $\mu$ is significantly greater than zero, and therefore the null hypothesis of a symmetric loss function for the ECB can be rejected, even at a confidence level of $1 \%$.

One criticism that can be made about these results is that they do not take into account the fact that, from November 1999 until June 2000, the ECB raised the interest rate of the main refinancing operations in five occasions. To the extent that this decisions were anticipated by the banks, they would have had an incentive to front-load their demands for liquidity, thereby putting an upward pressure on interbank rates. To check whether our estimate of $\mu$ may be biased by this effect, the first row of Table $2 b$ reports the results for a sample that excludes the data for the two weeks prior to an interest rate change, while the second row restricts the sample to the year 1999 in which there were two interest rate changes of opposite sign. As in Table $2 a$, the first column of Table $2 b$ uses Euribor- 7 as the interbank rate, while the last three columns use Eonia for, respectively, only the days of settlement of the tender, all days except the last days of the maintenance periods, and all days within the prespecified sample.

Table 2b Estimation of $\mu=E(r)-\widehat{r}$ for the period January 1999 - June 2000 under alternative samples.

\begin{tabular}{|c|c|c|c|c|}
\cline { 2 - 5 } \multicolumn{1}{c|}{} & $r=$ Euribor-7 & $r=$ Eonia & $r=$ Eonia & $r=$ Eonia \\
\hline$\hat{\mu}$ & .11 & .05 & .04 & .03 \\
$(s . e)$. & $(.01)$ & $(.02)$ & $(.01)$ & $(.01)$ \\
{$[p$-value $]$} & {$[.00]$} & {$[.01]$} & {$[.00]$} & {$[.00]$} \\
$n$ & 64 & 64 & 308 & 325 \\
\hline$\hat{\mu}$ & .10 & .03 & .04 & .03 \\
$(s . e)$. & $(.02)$ & $(.02)$ & $(.01)$ & $(.01)$ \\
{$[p$-value $]$} & {$[.00]$} & {$[.12]$} & {$[.00]$} & {$[.01]$} \\
$n$ & 51 & 51 & 247 & 259 \\
\hline
\end{tabular}

Moving from Table $2 \mathrm{a}$ to either the first or the second row of Table $2 \mathrm{~b}$ reduces the estimated value of $\mu$, so expectations about interest rate changes do seem to matter, but $\hat{\mu}$ is still significantly different from zero (except for the 1999 sample when only 
the days of settlement of the tender are considered). Hence we can safely reject the null hypothesis of a symmetric loss function for the ECB.

A more direct test of the null hypothesis $\gamma=0$ can be performed by exploiting the first order condition that characterizes the optimal decision of the central bank (see Lemma 1):

$$
E\left[(r-\widehat{r})+\gamma 1_{[r<\hat{r}]}(r-\widehat{r}) \mid \eta\right]=0 .
$$

Since according to our model the liquidity provided by the central bank in each tender, $s_{y}(\eta)$, is a function of the signal $\eta$, we can estimate $\gamma$ by the Generalized Method of Moments (GMM) using as instruments a constant and the liquidity effectively provided by the ECB through its main refinancing operations. ${ }^{17}$ The results for the four alternative samples considered in Table 2a are summarized in Table 3a. In this table we report the point estimate $\hat{\gamma}$, its standard error (robust to both heteroskedasticity and autocorrelation), the $p$-value of the one-sided test of the null hypothesis $\gamma=0$ (against the alternative $\gamma>0$ ), the $p$-value of the Sargan test, and the sample size.

Table 3a Estimation of the ECB's loss function parameter $\gamma$ for the period January 1999 - June 2000.

\begin{tabular}{|c|c|c|c|c|}
\cline { 2 - 5 } \multicolumn{1}{c|}{} & $r=$ Euribor-7 & $r=$ Eonia & $r=$ Eonia & $r=$ Eonia \\
\hline$\hat{\gamma}$ & 59.9 & 2.61 & 2.92 & 1.82 \\
$(s . e)$. & $(35.1)$ & $(1.58)$ & $(1.22)$ & $(.84)$ \\
{$[p$-value] } & {$[.04]$} & {$[.05]$} & {$[.01]$} & {$[.02]$} \\
Sargan [p-value] & {$[.45]$} & {$[.63]$} & {$[.53]$} & {$[.71]$} \\
$n$ & 76 & 76 & 367 & 385 \\
\hline
\end{tabular}

There are no substantial differences in the qualitative results in the four columns of Table 3: the null hypothesis of a symmetric loss function for the ECB can be rejected, and the instruments chosen pass the Sargan test without difficulty. The important quantitative difference in the estimated value of $\gamma$ using Euribor-7 (column 1) and Eonia (columns 2-4) is due to the fact that, as reported in Table 2a, the average differential between Euribor-7 and the rate of the main refinancing operations is 13

\footnotetext{
${ }^{17}$ Note that at each point in time there are two main refinancing operations outstanding, so we have taken as instrument the sum of amounts injected in them.
} 
basis points, while the differential between Eonia and this rate is only 7 or 8 basis points. In order to rationalize this difference within our model, we require a much higher value of $\gamma$ in the former case.

To check whether our estimate of $\gamma$ may be biased by expectations of changes in the stance of monetary policy (in particular interest rate increases), Table $3 \mathrm{~b}$ reports the results for the same samples as in Table 2a: the first row excludes the data for the two weeks prior to an interest rate change, while the second restricts the sample to the year 1999. As before, moving from Table $3 \mathrm{a}$ to Table $3 \mathrm{~b}$ reduces $\hat{\gamma}$, but for most of the cases we can still reject the null hypothesis of a symmetric loss function for the ECB (at a $10 \%$ confidence level).

Table 3b Estimation of the ECB's loss function parameter $\gamma$ for the period January 1999 - June 2000 under alternative samples.

\begin{tabular}{|c|c|c|c|c|}
\cline { 2 - 5 } \multicolumn{1}{c|}{} & $r$ = Euribor-7 & $r$ = Eonia & $r$ = Eonia & $r$ = Eonia \\
\hline$\hat{\gamma}$ & 43.6 & 1.43 & 1.54 & .82 \\
$(s . e)$. & $(26.7)$ & $(1.05)$ & $(.83)$ & $(.56)$ \\
{$[p$-value $]$} & {$[.05]$} & {$[.09]$} & {$[.03]$} & {$[.07]$} \\
Sargan $[p$-value] & {$[.49]$} & {$[.58]$} & {$[.98]$} & {$[.81]$} \\
$n$ & 64 & 64 & 308 & 325 \\
\hline$\hat{\gamma}$ & 46.3 & .67 & 1.18 & .60 \\
$($ s.e. $)$ & $(35.0)$ & $(.67)$ & $(.78)$ & $(.54)$ \\
{$[p$-value $]$} & {$[.09]$} & {$[.16]$} & {$[.07]$} & {$[.14]$} \\
Sargan $[p$-value $]$ & {$[.55]$} & {$[.75]$} & {$[.75]$} & {$[.96]$} \\
$n$ & 51 & 51 & 247 & 259 \\
\hline
\end{tabular}

All in all, the empirical evidence is consistent with an explanation of the overbidding by the banks in the fixed rate tenders conducted by the ECB until June 2000 based on its aversion to seeing interbank rates fall below the tender rate. The ECB then supplied less liquidity than that required to keep the average interbank rate at the level of the tender rate, and the banks run for the rents associated with the differential between these two rates.

As noted in the Introduction, the tender system used by the ECB in its main refinancing operations was changed to variable rate (American) tenders in June 2000. 
In its press release, the ECB noted that the switch to variable rate tenders should not be interpreted as a change in the stance of monetary policy, but simply a way to deal with the overbidding problem. Thus we have an ideal setting to check the predictions of our theoretical model.

In what follows we look at the evidence on three specific implications of our analysis of variable rate tenders: (i) the marginal auction rate should be equal to the expected interbank rate, (ii) the marginal rate should coincide with the average rate, ${ }^{18}$ and (iii) the degree of overbidding should be smaller than under fixed rate tenders. In addition, assuming that the loss function of the central bank is not altered by the change in the tender system (i.e. that the parameter $\gamma$ is the same), the difference between the marginal and the minimum bid rate should be equal to the difference between the expected interbank rate and the tender rate prior to the change.

The evidence on these predictions for the first 9 variable rate tenders conducted by the ECB is as follows. First, the mean spread between the interbank rate (for the days of settlement of the tender) and the marginal auction rate has been 8 basis points for the 1-week Euribor, and -1 basis point for Eonia. These figures are smaller that those observed under the previous system, and the one for Eonia is essentially zero. Second, the mean difference between the average and the marginal auction rate has only been 1 basis point. This is strikingly small, since one would have expected a fair amount of dispersion of the bids during an initial learning period. Third, the median allotment ratio has been $49.10 \%$, which is 8 times higher than the corresponding figure for the period under fixed rate tenders. Finally, the mean spread between the marginal and the minimum bid rate has been 7 basis points, which is in line with the estimated values of $\mu$ in Table 2a. Hence we conclude that the evidence collected so far from the variable rate tenders is consistent with the predictions of our model, although formal statistical testing will have to wait until there is more data.

\section{Concluding Remarks}

We have developed a model of the tender procedures used by the ECB in its open market operations. The model has two novel features. First we endogenize the

\footnotetext{
${ }^{18}$ This rate is the weighted average interest rate at which liquidity is supplied by the ECB.
} 
behavior of the central bank by postulating an objective function that depends on the deviations between the interbank rate and a target rate that characterizes the stance of monetary policy. Second we assume that there is an efficient interbank market in which the banks can always get liquidity, so their objective in participating in the central bank tenders is not to cover their liquidity needs but to profit from differentials between the interbank rate and the tender rate.

The analysis shows that when the central bank is more concerned about interbank rates below the target than about interbank rates above the target (i.e. when its objective function is asymmetric), fuxed rate tenders have a unique equilibrium characterized by extreme overbidding. The reason for this result is simple: the central bank tries to avoid low interbank rates by restricting the supply of liquidity, and this opens a differential between the expected interbank rate and the tender rate which the banks try to exploit by increasing the size of their bid. In contrast, variable rate tenders allow the banks to compete away this differential by offering higher rates, so in equilibrium they will be indifferent as to the amount bid (as long as the aggregate bid is sufficiently large to accommodate the central bank's desired liquidity injection).

Our empirical analysis based on the fixed rate tenders conducted by the ECB from January 1999 to June 2000 shows an average spread between the euro overnight interest rate and the tender rate of 4 or 5 basis points (depending on the way in which the sample is constructed). This spread is statistically different from zero, and supports the assumption of an asymmetric objective function for the ECB. In addition, the preliminary evidence from the variable rate tenders conducted from June 2000 is consistent with the predictions of our model.

The framework put forward in this paper is useful for analyzing a number of issues in variable rate tenders like the difference in the equilibrium outcomes of single rate and multiple rate tenders (there is none), the advantage of announcing the intended liquidity injection (there is now an equilibrium without overbidding), and the effect of introducing a minimum bid rate that signals the monetary policy stance (there is none as long as the central bank has an effective way of signalling this stance without it).

Finally, the framework may be useful for analyzing alternative tender procedures. 
For example, for a fixed rate tender in which the central bank commits to satisfy $100 \%$ of the bids of the banks at the target rate $\widehat{r}$, one can show that there is a unique symmetric equilibrium in which the representative bank bids an amount $b=$ $(\alpha-\widehat{r}) / \beta$ such that the expected equilibrium interbank rate $r$ is equal to the target rate $\widehat{r}$. Although there is no overbidding, the volatility of the interbank rate increases since now the central bank passively responds to the liquidity demands of the banks without taking into account its information on the autonomous liquidity creation and absorption factors. 


\section{Appendices}

\section{A The Interbank Market}

This Appendix presents a simple model that justifies the equilibrium interest rate equation (1) as well as the objective function (11) for the representative bank introduced in Section 2. The model incorporates some key elements of the monetary policy framework of the ECB, in particular the existence of (i) a reserve requirement determined on the basis of the banks' average daily reserve holdings over a one-month maintenance period, and (ii) lending and deposit standing facilities where banks can obtain or place liquidity, respectively, at interest rates $\widehat{r}^{l}$ and $\widehat{r}^{d}$ (with $\widehat{r}^{l}>\widehat{r}^{d}$ ).

Consider a model with three dates $(t=0,1,2)$. There is a representative bank that has to keep a level of reserves at dates $t=1,2$ (the maintenance period) such that

$$
\frac{1}{2}\left(l_{1}+l_{2}\right)=\phi d_{0}
$$

where $l_{t}$ denotes the reserves held at date $t=1,2, \phi$ is the reserve ratio, and $d_{0}$ is the reserve base. These reserves are initially borrowed from the central bank at date 0 for the whole maintenance period, and later adjusted in the overnight interbank market at dates $t=1,2$. If $l_{0}$ denotes the reserves borrowed (at the rate $\widehat{r}$ ) from the central bank, then $l_{t}-l_{0}$ are the reserves acquired by borrowing (at the rate $r_{t}$ ) in the interbank market at date $t=1,2$.

The supply of reserves at dates $t=1,2$ is given by $l_{1}=l_{0}+\nu_{1}+f_{1}$ and $l_{2}=$ $l_{1}+\nu_{2}+f_{2}-f_{1}$, respectively, where $l_{0}$ is the liquidity provided by the central bank at date $0, \nu_{1}$ and $\nu_{2}$ are iid continuous random shocks with zero mean, and $f_{1}$ and $f_{2}$ are the recourse to the credit (if positive) or deposit (if negative) facilities at dates $t=1,2$. Thus if the standing facilities are not used, reserves follow a random walk driven by the effect of the autonomous liquidity creation and absorption factors (like changes in cash holdings, net government deposits with the central bank, etc.).

At date 2 the representative bank is going to set $f_{2}$ in order to satisfy the reserve requirement (17). Equating the supply of reserves $l_{2}=l_{1}+\nu_{2}+f_{2}-f_{1}$ to the demand $l_{2}=2 \phi d_{0}-l_{1}$, and solving for $f_{2}$ then gives

$$
f_{2}=2\left(\phi d_{0}-l_{0}-\nu_{1}\right)-f_{1}-\nu_{2}
$$


By arbitrage, the equilibrium interbank rate at date 2 will be equal to the lending rate $\widehat{r}^{l}$ (the deposit rate $\widehat{r}^{d}$ ) if the representative bank uses the lending (deposit) standing facility. Hence we have

$$
r_{2}=\left\{\begin{array}{lll}
\widehat{r}^{l} & \text { if } & f_{2}>0 \\
\widehat{r}^{d} & \text { if } & f_{2}<0
\end{array} .\right.
$$

To determine the equilibrium interbank rate at date 1 we assume that the objective function of the representative bank is to minimize the expected cost of complying with the reserve requirement, that is

$$
\min _{l_{0}, l_{1}, l_{2}} E_{0}\left[2 l_{0} \widehat{r}+\left(l_{1}-l_{0}\right) r_{1}+\left(l_{2}-l_{0}\right) r_{2}\right]
$$

subject to (17). ${ }^{19}$ Substituting $l_{2}=2 \phi d_{0}-l_{1}$ from (17) into the objective function and rearranging yields

$$
\min _{l_{0}, l_{1}} E_{0}\left[l_{0}\left(\widehat{r}-r_{1}\right)+l_{0}\left(\widehat{r}-r_{2}\right)+l_{1}\left(r_{1}-r_{2}\right)+2 \phi d_{0} r_{2}\right] .
$$

Since this expression is linear in $l_{1}$, equilibrium requires

$$
r_{1}=E_{1}\left(r_{2}\right)
$$

Substituting (18) into this expression then gives

$$
r_{1}=\widehat{r}^{l} \operatorname{Pr}_{1}\left(f_{2}>0\right)+\widehat{r}^{d} \operatorname{Pr}_{1}\left(f_{2}<0\right)=\widehat{r}^{d}+\left(\widehat{r}^{l}-\widehat{r}^{d}\right) \operatorname{Pr}_{1}\left(f_{2}>0\right) .
$$

Hence the equilibrium interbank rate at date 1 will be between $\widehat{r}^{d}$ and $\widehat{r}^{l}$. This implies that the representative bank will not want use the standing facilities at date 1 , so $f_{1}=0$ and $f_{2}=2\left(\phi d_{0}-l_{0}-\nu_{1}\right)-\nu_{2}$. Since $f_{2}>0$ if and only if $\nu_{2}<2\left(\phi d_{0}-l_{0}-\nu_{1}\right)$, the equilibrium interbank rate at date 1 can be written as

$$
r_{1}=\widehat{r}^{d}+\left(\widehat{r}^{2}-\widehat{r}^{d}\right) G\left[2\left(\phi d_{0}-l_{0}-\nu_{1}\right)\right],
$$

where $G$ denotes the cumulative distribution function of the random liquidity shock $\nu_{2}$. According to this expression, the equilibrium interbank rate at date 1 is a decreasing function of the liquidity $l_{0}$ provided by the central bank at date 0 , and from the

\footnotetext{
${ }^{19}$ We are implicitly assuming that required reserves are not remunerated. If they were a negative constant term would appear in the objective function, but all the results would be unchanged. We also assume that the time intervals are sufficiently small so as to disregard any discounting of cash flows within the maintenance period.
} 
point of view of this date it is a random variable that depends on the realization of the liquidity shock $\nu_{1}$. These are the two main features of the equilibrium interest rate equation (1) introduced in Section 2, which can be seen as a first order approximation to $(20)^{20}$

Finally, substituting $r_{1}=E_{1}\left(r_{2}\right)$ into (19), and leaving out the constant term, we get the following objective function for the representative bank

$$
\min _{l_{0}} E_{0}\left[l_{0}\left(\widehat{r}-r_{1}\right)+l_{0}\left(\hat{r}-r_{2}\right)\right] \text {. }
$$

This function extends to the case of two-period central bank loans the objective function (11) in Section 2.

\section{B Proofs}

Proof of Lemma 1 Substituting (1) and (2) into the objective function (3) leads to the problem

$$
\min _{l} E\left[(\alpha-\beta l+\eta+u-\widehat{r})^{2} \mid \eta\right]+\gamma \int_{-\infty}^{u(l)}(\alpha-\beta l+\eta+u-\widehat{r})^{2} d F(u),
$$

where $u(l)$ satisfies $\alpha-\beta l+\eta+u(l)=\widehat{r}$. The corresponding first order condition that implicitly defines $s_{\gamma}(\eta)$ is

$$
\alpha-\beta l+\eta-\hat{r}+\gamma \int_{-\infty}^{u(l)}(\alpha-\beta l+\eta+u-\widehat{r}) d F(u)=0 .
$$

Integrating by parts the last term on the LHS, this condition simplifies to

$$
\alpha-\beta l+\eta-\widehat{r}-\gamma \int_{-\infty}^{u(l)} F(u) d u=0 .
$$

Differentiating this expression then gives

$$
\frac{\partial s_{\gamma}(\eta)}{\partial \eta}=\frac{1+\gamma F(u(l))}{\beta[1+\gamma F(u(l))]}=\frac{1}{\beta}
$$

and

$$
\frac{\partial s_{\gamma}(\eta)}{\partial \gamma}=-\frac{\int_{-\infty}^{u(l)} F(u) d u}{\beta[1+\gamma F(u(l))]}<0 .
$$

Hence the function $s_{\gamma}(\eta)$ is linear in $\eta$, with slope $1 / \beta$ and an intercept that is decreasing in $\gamma$, so we get (4) with $r_{\gamma}$ increasing in $\gamma$. Finally, for $\gamma=0$ we can explicitly solve the first order condition to get $s_{0}(\eta)=(\alpha-\widehat{r}+\eta) / \beta$, which implies $r_{0}=\widehat{r}$.

\footnotetext{
${ }^{20}$ This approximation would be exact if the distribution of the liquidity shocks were uniform.
} 
Proof of Lemma 2 Substituting (10) and (2) into the objective function (3) leads to the problem

$$
\begin{aligned}
\min _{s} E\left[\left(\alpha-\beta \min \left\{b^{*}, s\right\}+\eta+u-\widehat{\tau}\right)^{2} \mid \eta\right] \\
\quad+\gamma \int_{-\infty}^{u(s)}\left(\alpha-\beta \min \left\{b^{*}, s\right\}+\eta+u-\widehat{\tau}\right)^{2} d F(u),
\end{aligned}
$$

where $u(s)$ satisfies $\alpha-\beta \min \left\{b^{*}, s\right\}+\eta+u(s)=\widehat{r}$. The function to be minimized coincides with the convex function in (21) for $s \leq b^{*}$, and it is constant for $s \geq b^{*}$. Hence if $s_{\gamma}(\eta) \leq b^{*}$, it is clear that $s=s_{\gamma}(\eta)$ is also the unique solution to the central bank's problem. On the other hand, if $s_{\gamma}(\eta)>b^{*}$ then any $s \geq b^{*}$ will be a solution, so we can take $s=s_{\gamma}\left(r_{i}\right)$.

Proof of Proposition 1 Substituting (8) and (10) into (11), and using the result in Lenuna 2, gives the following objective function for the representative bank

$$
b E\left[\min \left\{1, \frac{s_{\gamma}(\eta)}{b^{*}}\right\}\left(\alpha-\beta \min \left\{b^{*}, s_{\gamma}(\eta)\right\}+\varepsilon-\widehat{r}\right)\right] .
$$

Since this function is linear in the bid $b$, the bank's optimal behavior is to bid the maximum amount $c$ if the coefficient of $b$ is positive, and any $b \in[0, c]$ if it is zero. One can show that

$$
\begin{aligned}
& E\left[\min \left\{1, \frac{s_{\gamma}(\eta)}{b^{*}}\right\}\left(\alpha-\beta \min \left\{b^{*}, s_{\gamma}(\eta)\right\}+\varepsilon-\widehat{\tau}\right)\right] \\
& =E\left[E\left(\min \left\{1, \frac{s_{\gamma}(\eta)}{b^{*}}\right\}\left(\alpha-\beta \min \left\{b^{*}, s_{\gamma}(\eta)\right\}+\varepsilon-\widehat{\tau}\right) \mid \eta\right)\right] \\
& =E\left[\min \left\{1, \frac{s_{\gamma}(\eta)}{b^{*}}\right\}\left(\alpha-\beta \min \left\{b^{*}, s_{\gamma}(\eta)\right\}+\eta-\widehat{r}\right)\right] \\
& =E\left[\min \left\{1, \frac{s_{\gamma}(\eta)}{b^{*}}\right\}\left[\beta\left(s_{\gamma}(\eta)-\min \left\{b^{*}, s_{\gamma}(\eta)\right\}\right)+r_{\gamma}-\widehat{r}\right]\right] \\
& =E\left[\beta \max \left\{s_{\gamma}(\eta)-b^{*}, 0\right\}+\min \left\{1, \frac{s_{\gamma}(\eta)}{b^{*}}\right\}\left(r_{\gamma}-\widehat{r}\right)\right] \\
& \geq \beta E\left[\max \left\{s_{\gamma}(\eta)-b^{*}, 0\right\}\right],
\end{aligned}
$$


with strict inequality for $\gamma>0$, where the first equality follows from the law of iterated expectations, the second from the application of the conditional expectations operator, the third from the definition of $s_{\gamma}(\eta)$, the fourth from that fact that $s_{\gamma}(\eta)-$ $\min \left\{b^{*}, s_{\gamma}(\eta)\right\}=\max \left\{s_{\gamma}(\eta)-b^{*}, 0\right\}=0$ whenever $\min \left\{1, s_{\gamma}(\eta) / b^{*}\right\}<1$, and the inequality follows from (6) together with the result that $r_{\gamma}$ is increasing in $\gamma$ with $r_{0}=\hat{r}$.

Now $E\left[\max \left\{s_{\gamma}(\eta)-b^{*}, 0\right\}\right] \geq 0$ implies that for $\gamma>0$ the representative bank has an incentive to set $b=c$. On the other hand, for $\gamma=0$, if $b^{*}<s_{0}(\bar{\eta})$ we have $E\left[\max \left\{s_{0}(\eta)-b^{*}, 0\right\}\right]>0$, so the bank has an incentive to set $b=c$, which contradicts the assumption $b^{*}<s_{0}(\bar{\eta})<c$. Hence it must be the case that $b^{*} \geq s_{0}(\bar{\eta})$, in which case $E\left[\max \left\{s_{0}(\eta)-b^{*}, 0\right\}\right]=0$ and any $b \in\left[s_{0}(\bar{\eta}), c\right]$ constitutes an equilibrium.

Proof of Proposition 2 From the proof of Proposition 1, it is clear that the objective function of the representative bank now becomes

$$
b\left[\min \left\{1, \frac{s_{\gamma}(\eta)}{b^{*}}\right\}\left(\alpha-\beta \min \left\{b^{*}, s_{\gamma}(\eta)\right\}+\eta-\widehat{r}\right)\right] .
$$

We have shown that

$$
\min \left\{1, \frac{s_{\gamma}(\eta)}{b^{*}}\right\}\left(\alpha-\beta \min \left\{b^{*}, s_{\gamma}(\eta)\right\}+\eta-\widehat{r}\right) \geq \beta \max \left\{s_{\gamma}(\eta)-b^{*}, 0\right\}
$$

with strict inequality for $\gamma>0$. Now $\max \left\{s_{\gamma}(\eta)-b^{*}, 0\right\} \geq 0$ implies that for $\gamma>0$ the representative bank has an incentive to set $b=c$. On the other hand, for $\gamma=0$, if $b^{*}<s_{0}(\eta)$ we have $\max \left\{s_{0}(\eta)-b^{*}, 0\right\}>0$, so the bank has an incentive to set $b=c$, which contradicts the assumption $b^{*}<s_{0}(\eta)<c$. Hence it must be the case that $b^{*} \geq s_{0}(\eta)$, in which case any $b \in\left[s_{0}(\eta), c\right]$ constitutes an equilibrium.

Proof of Proposition 3 Following the same steps as in the proof of Proposition 1 one can show that if the representative bank offers an interest rate $\vec{r}=\vec{r}^{*}$ its objective function becomes

$$
\begin{aligned}
& b E\left[\min \left\{1, \frac{s_{\gamma}(\eta)}{b^{*}}\right\}\left(\alpha-\beta \min \left\{b^{*}, s_{\gamma}(\eta)\right\}+\varepsilon-\widetilde{r}^{*}\right)\right] \\
& =b E\left[\beta \max \left\{s_{\gamma}(\eta)-b^{*}, 0\right\}+\min \left\{1, \frac{s_{\gamma}(\eta)}{b^{*}}\right\}\left(r_{\gamma}-\widetilde{r}^{*}\right)\right] .
\end{aligned}
$$


There are two cases to consider. First suppose that

$$
E\left[\beta \max \left\{s_{\gamma}(\eta)-b^{*}, 0\right\}+\min \left\{1, \frac{s_{\gamma}(\eta)}{b^{*}}\right\}\left(r_{\gamma}-\widetilde{r}^{*}\right)\right]>0 .
$$

Then we can only have an equilibrium with $b^{*}=c$, which by assumption (7) implies $s_{\gamma}(\bar{\eta})<b^{*}$, so the previous expression reduces to

$$
E\left[\frac{s_{\gamma}(\eta)}{b^{*}}\left(r_{\gamma}-\widetilde{r}^{*}\right)\right]=\frac{E\left[s_{\gamma}(\eta)\right]}{b^{*}}\left(r_{\gamma}-\widetilde{r}^{*}\right)>0 .
$$

Now if the representative bank were to offer $\widetilde{r}>\widetilde{r}^{*}$ its objective function would become

$$
b E\left[\alpha-\beta s_{\gamma}(\eta)+\eta-\widetilde{r}^{*}\right]=b\left(r_{\gamma}-\widetilde{r}^{*}\right) .
$$

But then

$$
r_{\gamma}-\widetilde{r}^{*}>\frac{E\left[s_{\gamma}(\eta)\right]}{b^{*}}\left(r_{\gamma}-\widetilde{r}^{*}\right)>0
$$

implies that the representative bank has an incentive to deviate from $\tilde{r}=\widetilde{r}^{*}$, so there is no equilibrium in this case.

Next suppose that

$$
E\left[\beta \max \left\{s_{\gamma}(\eta)-b^{*}, 0\right\}+\min \left\{1, \frac{s_{\gamma}(\eta)}{b^{*}}\right\}\left(r_{\gamma}-\widetilde{r}^{*}\right)\right]=0 .
$$

If $s_{\gamma}(\bar{\eta})>b^{*}$ we have $E\left[\max \left\{s_{\gamma}(\eta)-b^{*}, 0\right\}\right]>0$, so it must be the case that $r_{\gamma}<\widetilde{r}^{*}$. Now if the representative bank were to offer $\widetilde{r}=r_{\gamma}<\widetilde{r}^{*}$ its objective function would become

$$
b E\left[\alpha-\beta b^{*}+\eta-r_{\gamma} \mid s_{\gamma}(\eta)>b^{*}\right] \operatorname{Pr}\left(s_{\gamma}(\eta)>b^{*}\right) .
$$

But since

$$
E\left[\alpha-\beta b^{*}+\eta-r_{\gamma} \mid s_{\gamma}(\eta)>b^{*}\right]=E\left[\beta\left(s_{\gamma}(\eta)-b^{*}\right) \mid s_{\gamma}(\eta)>b^{*}\right]>0
$$

the bank has an incentive to deviate from $\tilde{r}=\tilde{r}^{*}$. Finally, if $s_{\gamma}(\bar{\eta}) \leq b^{*}$ the expression at the beginning of this paragraph reduces to,

$$
\frac{E\left[s_{\gamma}(\eta)\right]}{b^{*}}\left(r_{\gamma}-\tilde{r}^{*}\right)=0,
$$

which implies $r_{\gamma}=\tilde{r}^{*}$. Now if the representative bank were to deviate by offering $\widetilde{r}<\widetilde{r}^{*}$ its payoff would be zero, while if it offered $\widetilde{r}>\widetilde{r}^{*}$ its objective function would become $b\left(r_{\gamma}-\tilde{r}^{*}\right)=0$. Hence any bid $b \in\left[s_{\gamma}(\bar{\eta}), c\right]$ at the rate $r=r_{\gamma}$ constitutes an equilibrium. 
Proof of Proposition 4 From the proof of Proposition 3, it is clear that if the representative bank offers an interest rate $\tilde{r}=\widetilde{r}^{*}$ its objective function becomes

$$
b\left[\beta \max \left\{s_{\gamma}(\eta)-b^{*}, 0\right\}+\min \left\{1, \frac{s_{\gamma}(\eta)}{b^{*}}\right\}\left(r_{\gamma}-\widetilde{r}^{*}\right)\right] .
$$

As before there are two cases to consider. First suppose that

$$
\beta \max \left\{s_{\gamma}(\eta)-b^{*}, 0\right\}+\min \left\{1, \frac{s_{\gamma}(\eta)}{b^{*}}\right\}\left(r_{\gamma}-\widetilde{r}^{*}\right)>0 .
$$

Then we can only have an equilibrium with $b^{*}=c$, which by assumption (7) implies $s_{\gamma}(\eta)<b^{*}$, so the previous expression reduces to

$$
\frac{s_{\gamma}(\eta)}{b^{*}}\left(r_{\gamma}-\widetilde{r}^{*}\right)>0
$$

Now if the representative bank were to offer $\tilde{r}>\widetilde{r}^{*}$ its objective function would become

$$
b\left[\alpha-\beta s_{\gamma}(\eta)+\eta-\widetilde{r}^{*}\right]=b\left(r_{\gamma}-\widetilde{r}^{*}\right)
$$

But then

$$
r_{\gamma}-\widetilde{r}^{*}>\frac{s_{\gamma}(\eta)}{b^{*}}\left(r_{\gamma}-\widetilde{r}^{*}\right)>0
$$

implies that the representative bank has an incentive to deviate from $\tilde{r}=\widetilde{r}^{*}$, so there is no equilibrium in this case.

Next suppose that

$$
\beta \max \left\{s_{\gamma}(\eta)-b^{*}, 0\right\}+\min \left\{1, \frac{s_{\gamma}(\eta)}{b^{*}}\right\}\left(r_{\gamma}-\widetilde{r}^{*}\right)=0 .
$$

If $s_{\gamma}(\eta)>b^{*}$ we have $\max \left\{s_{\gamma}(\eta)-b^{*}, 0\right\}>0$, so it must be the case that $r_{\gamma}<\tilde{r}^{*}$. Now if the representative bank were to offer $\tilde{r}=r_{\gamma}<\widetilde{r}^{*}$ its objective function would become $b \beta\left(s_{\gamma}(\eta)-b^{*}\right)$, so the bank has an incentive to deviate from $\tilde{r}=\widetilde{r}^{*}$. Finally, if $s_{\gamma}(\eta) \leq b^{*}$ the expression at the beginning of this paragraph reduces to,

$$
\frac{s_{\gamma}(\eta)}{b^{*}}\left(r_{\gamma}-\widetilde{r}^{*}\right)=0
$$

which implies $r_{\gamma}=\widetilde{r}^{*}$. Now if the representative bank were to deviate by offering $\tilde{r}<\widetilde{r}^{*}$ its payoff would be zero, while if it offered $\tilde{r}>\widetilde{r}^{*}$ its objective function would become $b\left(r_{\gamma}-\widetilde{r}^{*}\right)=0$. Hence any bid $b \in\left[s_{\gamma}(\eta), c\right]$ at the rate $r_{\gamma}$ constitutes an equilibrium. 
Proof of Proposition 5 The result for the case where $b(c) \in[0, c]$ follows immediately from the arguments in the proof of Proposition 1. For the case $b(c) \in[0, \bar{b}$, the same arguments as in the proof of Proposition 1 imply that when $\gamma>0$ the banks have an incentive to bid the maximum amount compatible with having enough collateral to cover the allotted amount, which gives (15). To prove uniqueness let us define

$$
D\left(b^{*}\right)=\int_{0}^{\bar{c}} \min \left\{\frac{b^{*} c}{s_{\gamma}(\bar{\eta})}, \bar{b}\right\} d H(c) .
$$

This function is continuous and satisfies

$$
D\left(b^{*}\right)=\frac{b^{*}}{s_{\gamma}(\bar{\eta})} \int_{0}^{\bar{c}} c d H(c), \quad \text { for } b^{*} \leq \vec{b}=\frac{s_{\gamma}(\bar{\eta}) \bar{b}}{\bar{c}}
$$

and

$$
D\left(b^{*}\right)=\frac{b^{*}}{s_{\gamma}(\bar{\eta})} \int_{0}^{c\left(b^{*}\right)} c d H(c)+\bar{b} \int_{c\left(b^{*}\right)}^{\bar{c}} d H(c), \text { for } b^{*}>\bar{b}^{*},
$$

where

$$
c\left(b^{*}\right)=\frac{s_{\gamma}(\bar{\eta}) \bar{b}}{b^{*}} .
$$

Hence for $b^{*} \leq \bar{b}^{*}$ the function $D\left(b^{*}\right)$ is linear, and by assumption (14) has a slope greater than one, and for $b^{*}>\bar{b}^{*}$ one can check that

$$
D^{\prime}\left(b^{*}\right)=\frac{1}{s_{\gamma}(\bar{\eta})} \int_{0}^{c\left(b^{*}\right)} c d H(c)>0,
$$

$D^{\prime \prime}\left(b^{*}\right)<0$, and $\lim _{b^{*} \rightarrow \infty} D\left(b^{*}\right)=\bar{b}$, so the equation $D\left(b^{*}\right)=b^{*}$ has a unique solution. Finally, the result for $\gamma=0$ follows immediately from the arguments in the proof of Proposition 1.

Proof of Proposition 6 Follows immediately from the arguments in the proof of Proposition 3. 



\section{References}

[1] Bindseil, Ulrich (2000), "Forecasting Autonomous Liquidity Factors: Quality, Publication and the Control of the Overnight Rate", mimeo.

[2] Campbell, John Y. (1987), "Money Announcements, the Demand for Bank Reserves, and the Behavior of the Federal Fund Rate within the Statement Week", Journal of Money, Credit, and Banking, 19, pp. 56-67.

[3] Catalāo Lopes, Margarida (2000), "Financing in the Eurosystem: Fixed versus Variable Rate Tenders", mimeo.

[4] European Central Bank (1998), The Single Monetary Policy in Stage Three. General Documentation on ESCB Monetary Policy Instruments and Procedures, Frankfort am Main.

[5] European Central Bank (2000), Annual Report 1999, Frankfort am Main.

[6] Favero, Carlo, et al. (2000), One Money, Many Countries, Monitoring the European Central Bank 2, Centre for Economic Policy Research, London.

[7] Hamilton, James D., (1996), "The Daily Market for Federal Funds", Journal of Political Economy, 104, pp. 25-56.

[8] International Monetary Fund (1999), International Capital Markets. Developments, Prospects, and Key Policy Issues, Washington.

[9] Nautz, Dieter, and Jörg Oechssler (1999), "The Repo Auctions of the European Central Bank and the Vanishing Quota Puzzle", Discussion Paper No. 79, SFB 373, Humboldt-University Berlin.

[10] Pérez-Quirós, Gabriel, and Hugo Rodríguez-Mendizábal (2000), "The Daily Market for Funds in Europe: Has Something Changed with EMU?", mimeo. 



\section{WORKING PAPERS (1)}

9708 Jefírey Franks: Labor market policies and unemployment dynamics in Spain

9709 José Ramón Martínez Resano: Los mercados de derivados y el euro.

9710 Juan Ayuso and J. David López-Salido: Are ex-post real interest rates a good proxy for ex-ante real rates? An international comparison within a CCAPM framework.

9711 Ana Buisán y Miguel Pérez: Un indicador de gasto en construcción para la economía española.

9712 Juan J. Dolado, J. David López-Salido and Juan Luis Vega: Spanish unemployment and inflation persistence: Are there phillips trade-offs?

9713 José M. González Mínguez: The balance-sheet transmission channel of monetary policy: The cases of Germany and Spain.

9714 Olympia Bover: Cambios en la composición del empleo y actividad laboral femenina.

9715 Francisco de Castro and Alfonso Novales: The joint dynamics of spot and forward exchange rates.

9716 Juan Carlos Caballero, Jorge Martínez y M. ${ }^{\circledR 2}$ Teresa Sastre: La utilización de los índices de condiciones monetarias desde la perspectiva de un banco central.

9717 José Viñals y Juan F. Jimeno: El mercado de trabajo español y la Unión Económica y Monetaria Europea.

9718 Samuel Bentolila: La inmovilidad del trabajo en las regiones españolas.

9719 Enrique Alberola, Juan Ayuso and J. David López-Salido: When may peseta depreciations fuel inflation?

9720 José M. González Mínguez: The back calculation of nominal historical series after the introduction of the european currency (An application to the GDP).

9721 Una-Louise Bell: A Comparative Analysis of the Aggregate Matching Process in France, Great Britain and Spain.

9722 Francisco Alonso Sánchez, Juan Ayuso Huertas y Jorge Martínez Pagés: El poder predictivo de los tipos de interés sobre la tasa de inflación española.

9723 Isabel Argimón, Concha Artola y José Manuel González-Páramo: Empresa pública y empresa privada: titularidad y eficiencia relativa.

9724 Enrique Alberola and Pierfederico Asdrubali: How do countries smooth regional disturbances? Risksharing in Spain: 1973-1993.

9725 Enrique Alberola, José Manuel Marqués and Alicia Sanchís: Unemployment persistence. Central Bank independence and inflation performance in the OECD countries. (The Spanish original of this publication has the same number.)

9726 Francisco Alonso, Juan Ayuso and Jorge Martínez Pagés: How informative are financial as set prices in Spain?

9727 Javier Andrés, Ricardo Mestre and Javier Vallés: Monetary policy and exchange rate dynamics in the Spanish economy.

9728 Juan J. Dolado, José M. González-Páramo y José Viñals: A cost-benefit analysis of going from low inflation to price stability in Spain. 
9801 Ángel Estrada, Pilar García Perea, Alberto Urtasun y Jesús Briones: Indicadores de precios, costes y márgenes en las diversas ramas productivas.

9802 Pilar Álvarez Canal: Evolución de la banca extranjera en el período 1992-1996.

9803 Ángel Estrada y Alberto Urtasun: Cuantificación de expectativas a partir de las encuestas de opinión.

9804 Soyoung Kim: Monetary Policy Rules and Business Cycles.

9805 Víctor Gómez and Agustín Maravall: Guide for using the programs TRAMO and SEATS.

9806 Javier Andrés, Ignacio Hernando and J. David López-Salido: Disinflation, output and unemployment: the case of Spain.

9807 Olympia Bover, Pilar García-Perea and Pedro Portugal: A comparative study of the Portuguese and Spanish labour markets.

9808 Víctor Gómez and Agustín Maravall: Automatic modeling methods for univariate series.

9809 Víctor Gómez and Agustín Maravall: Seasonal adjustment and signal extraction in economic time series.

9810 Pablo Hernández de Cos e Ignacio Hernando: El crédito comercial en las empresas manufactureras españolas.

9811 Soyoung Kim: Identifying European Monetary Policy Interactions: French and Spanish System with German Variables.

9812 Juan Ayuso, Roberto Blanco y Alicia Sanchís: Una clasificación por riesgo de los fondos de inversión españoles.

9813 José Viñals: The retreat of inflation and the making of monetary policy: where do we stand?

9814 Juan A yuso, Graciela L. Kaminsky and David López-Salido: A switching-regime model for the Spanish inflation: 1962-1997.

9815 Roberto Blanco: Transmisión de información y volatilidad entre el mercado de futuros sobre el índice Ibex 35 y el mercado al contado.

9816 M.* Cruz Manzano and Isabel Sánchez: Indicators of short-term interest rate expectations. The information contained in the options market. (The Spanish original of this publication has the same number.)

9817 Alberto Cabrero, José Luis Escrivá, Emilio Muñoz and Juan Peñalosa: The controllability of a monetary aggregate in EMU.

9818 José M. González Mínguez y Javier Santillán Fraile: El papel del euro en el Sistema Monetario Internacional.

9819 Eva Ortega: The Spanish business cycle and its relationship to Europe.

9820 Eva Ortega: Comparing Evaluation Methodologies for Stochastic Dynamic General Equilibrium Models.

9821 Eva Ortega: Assessing the fit of simulated multivariate dynamic models.

9822 Coral García y Esther Gordo: Funciones trimestrales de exportación e importación para la economía española.

9823 Enrique Alberola-Ila and Timo Tyrväinen: Is there scope for inflation differentials in EMU? An empirical evaluation of the Balassa-Samuelson model in EMU countries.

9824 Concha Artola e Isabel Argimón: Titularidad y eficiencia relativa en las manufacturas españolas. 
9825 Javier Andrés, Ignacio Hernando and J. David López-Salido: The long-run effect of permanent disinflations.

9901 José Ramón Martínez Resano: Instrumentos derivados de los tipos Overnight: call money swaps y futuros sobre fondos federales.

9902 J. Andrés, J. D. López-Salido and J. Vallés: The liquidity effect in a small open economy model.

9903 Olympia Bover and Ramón Gómez: Another look at unemployment duration: long-term unemployment and exit to a permanent job. (The Spanish original of this publication has the same number.)

9904 Ignacio Hernando y Josep A. Tribó: Relación entre contratos laborales y financieros: Un estudio teórico para el caso español.

9905 Cristina Mazón and Soledad Núñez: On the optimality of treasury bond auctions: the Spanish case.

9906 Nadine Watson: Bank Lending Channel Evidence at the Firm Level.

9907 José Viñals: El marco general de la política monetaria única: racionalidad, consecuencias y cuestiones pendientes.

9908 Olympia Bover and Manuel Arellano: Learning about migration decisions from the migrants: an exercise in endogenous samplig and complementary datasets.

9909 Olympia Bover and Pilar Velilla: Migrations in Spain: Historical background and current trends.

9910 Fernando Restoy: Los mercados financieros españoles ante la Unión Monetaria.

9911 Luis J. Álvarez and M. a de los Llanos Matea: Underlying inflation measures in Spain.

9912 Regina Kaiser and Agustín Maravall: Estimation of the business cycle: a modified HodrickPrescott filter.

9913 Enrique Alberola and José Manuel Marqués: On the relevance and nature of regional inflation differentials: The case of Spain.

9914 Agustín Maravall: An application of TRAMO and SEATS. Report for the «Seasonal Adjustment Research Appraisal» project.

9915 Regina Kaiser and Agustín Maravall: Seasonal outliers in time series.

9916 Enrique Alberola and Humberto López: Internal and external exchange rate equilibrium in a cointegration framework. An application to the Spanish Peseta.

9917 José Viñals and Javier Vallés: On the real effects of monetary policy.

9918 Regina Kaiser and Agustín Maravall: Short-term and long-term trends, seasonal adjustment, and the business cycle.

9919 J. Andrés, J. D. López-Salido and J. Vallés: Intertemporal substitution and the liquidity effect in a sticky price model.

9920 J. Andrés, I. Hernando and J. D. López-Salidø: The role of the financial system in the growth-inflation link: The OECD experience.

9921 Ángel Estrada and Ignacio Hernando: Microeconomic price adjustments and inflation: Evidence from Spanish sectoral data.

9922 Concha Artola and Una-Louise Bell: Identifying Labour Market Dynamics using Labour Force Survey Data. 
9923 Juan Ayuso and Roberto Blanco: Has financial market integration increased during the nineties?

9924 Ignacio Fuentes and Teresa Sastre: Merkers and acquisitions in the Spanish Banking industry: some empirical evidence.

0001 Georges Siotis: Market power, total factor productivity growth, and structural change. An illustration for Spain, 1983-1996.

0002 Alberto Cabrero: Seasonal adjustment in economic time series: The experience of the Banco de España (with the model-based method)

0003 Luis Gordo and Pablo Hernández de Cos: The financing arrangements for the regional (autonomous) governments for the period 1997-2001. (The Spanish original of this publication has the same number.)

0004 J. Andrés, F. Ballabriga and J. Vallés: Monetary Policy and Exchange Rate Behavior in the Fiscal Theory of the Price Level.

0005 Michael Binder, Cheng Hsiao and M. Hashem Pesaran: Estimation and Inference in Short Panel Vector Autoregressions with Unit Roots and Cointegration.

0006 Enrique Alberola and Luis Molina: Fiscal discipline \& Exchange Rate Regimes. A case for currency Boards?

0007 Soledad Núñez y Miguel Pérez: La rama de servicios en España: un análisis comparado.

0008 Olympia Bover and Nadine Watson: Are There Economies of Scale in the Demand for Money by Firms? Some Panel Data Estimates.

0009 Ángel Estrada, Ignacio Hernando and J. David López-Salido: Measuring the NAIRU in the Spanish Economy.

0010 Eva Ortega y Enrique Alberola: Transmisión de shocks y política monetaria en la UEM. Un ejercicio con NIGEM.

0011 Regina Kaiser and Agustín Maravall: An Application of TRAMO-SEATS: Changes in Seasonality and Current Trend-Cycle Assessment. The German Retail Trade Turnover Series.

0012 Regina Kaiser and Agustín Maravall: Notes on Time Series Analysis, ARIMA Models and Signal Extraction.

0013 Jordi Galí, J. David López-Salido and Javier Vallés: Technology Shocks and Monetary Policy: Assessing the Fed's Performance.

0014 Agustín Maravall and Fernando J. Sánchez: An Application of TRAMO-SEATS: Model Selection and Out-of-sample Performance. The Swiss CPI series.

0015 Olympia Bover, Samuel Bentolila, and Manuel Arellano: The Distribution of Eamings in Spain during the 1980s: The Effects of Skill, Unemployment, and Union Power.

0016 Juan Ayuso and Rafael RepuIlo: A Model of the Open Market Operations of the European Central Bank.

(1) Previously published Working Papers are listed in the Banco de España publications catalogue.

Queries should be addressed to: Banco de España

Sección de Publicaciones. Negociado de Distribución y Gestión

Telephone: 913385180

Alcalá, 50. 28014 Madrid 